\title{
Avances en inmunoterapia celular contra el melanoma maligno
}

\author{
Mercedes López ${ }^{1}$, Alejandro Escobar ${ }^{1 a}$, Jorge Alfaro ${ }^{2}$, \\ Miguel Fodor ${ }^{2}$, Milton Larrondo ${ }^{2}$, Carlos Ferrada ${ }^{2,3}$, \\ Flavio Salazar-Onfray ${ }^{1 b}$.

\section{Advances in cellular immunotherapy for malignant melanoma}

An alternative strategy for cancer treatment is the manipulation of the immune system, denominated cancer immunotherapy. The immunotherapeutical use of cells of the immune system, like dendritic cells (DC), is being explored in different clinical protocols. Recently, we finalized a clinical phase I protocol, for the treatment of malignant melanoma, using DCs loaded with tumor lysates. Our results indicate that the subcutaneous application of DCs do not produce adverse effects. We also observed an increase of tumor specific T lymphocytes precursors in the blood, associated to hypersensitivity reactions (DTH) in $60 \%$ of the treated patients. In most cases, an stability in the disease was observed, although without a significant association between vaccination and survival. Additionally, therapies based on Interleukin-2 (IL-2) have been used with relative success in the treatment of some kind of tumors since 1985. However, problems associated to the toxicity of IL-2 still restrict its massive use. Our direct experience with the use of IL-2, indicates that low doses and its subcutaneous application, maintains the beneficial effects for patients, eliminating the adverse effects. Based on the accumulated evidence during last the five years, we decided to implement an optimized clinical protocol, which alternatively combines dendritic cells vaccines with the use of low doses of IL-2 for the reinforcement of the immunological system (Rev Méd Chile 2004; 132: 1115-26).

(Key Words: Dendritic cells; Immunotherapy; Interleukin-2; Malignant melanoma)

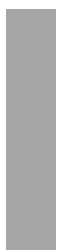

Recibido el 8 de abril, 2004. Aceptado el 6 de julio, 2004.

Trabajo financiado por FONDEF DO2I1088.

${ }^{1}$ Programa Disciplinario de Inmunología, Instituto de Ciencias Biomédicas Prof. Dr. Eduardo Cruz-Coke Lassabe, Facultad de Medicina, Universidad de Chile. ${ }^{2}$ Hospital Clínico José Joaquín Aguirre, Universidad de Chile. ${ }^{3}$ Clínica Alemana.

aMédico Veterinario, Magister en Inmunología (MSc)

bBiólogo, Doctor en Ciencias Médicas (PhD)

Correspondencia a: Dr. Flavio Salazar-Onfray. Programa Disciplinario de Inmunología, Instituto de Ciencias Biomédicas, Facultad de Medicina, Universidad de Chile. Av Independencia 1027, Independencia. Fono: 6786345. Fax: 7353346. E mail: fsalazar@med.uchile.cl 
$\mathrm{E}^{1}$ melanoma es un tumor maligno de origen neuroectodérmico, que se desarrolla a partir de melanocitos cutáneos y de células pigmentarias del iris y uvea y cuya incidencia ha aumentado progresivamente en el último siglo. La única forma de curar un melanoma maligno es su detección precoz y un tratamiento quirúrgico idóneo, ya que una vez que llega a un estado avanzado, es altamente resistente al tratamiento convencional de radio y quimioterapia ${ }^{1}$. Esta situación también se repite en Chile, donde solamente en Santiago, entre los años 1992 y 1996 se detectaron 318 casos de melanoma maligno, lo que equivale a $10,6 \%$ de todos los tipos de cáncer de piel2 ${ }^{2}$. Debido a la ineficacia de los tratamientos convencionales en el tratamiento del melanoma avanzado, resulta indispensable la implementación de nuevas terapias, especialmente en pacientes con melanoma en etapa III y IV.

\section{TERAPIAS INMUNOLÓGICAS ACTUALES EN CÁNCER}

Pese al desarrollo de modernas técnicas de cirugía y trasplantes, nuevas y más efectivas drogas citotóxicas y mejores métodos de irradiación, que han permitido tratar con éxito algunas patologías neoplásicas, como la leucemia infan$\mathrm{til}^{3}$, frecuentemente, algunas células malignas sobreviven a estas terapias y se diseminan en el organismo, haciendo necesario el desarrollo de nuevos tratamientos complementarios a los actuales. Uno de estos métodos es la manipulación del sistema inmune para combatir tumores, lo que se denomina inmunoterapia del cáncer. A partir de la década 1980-89, cuando se logró aislar linfocitos T citotóxicos (CTL) con actividad antitumoral de sangre periférica, ganglios linfáticos y tejido tumoral de pacientes con melanoma, se ha producido un creciente interés por utilizar el sistema inmune como herramienta en el tratamiento del cáncer. Citoquinas como interleuquina 2 (IL-2), interferón gamma (IFN- $\gamma$ ) e interferón alfa (IFN- $\alpha$ ) son comúnmente utilizadas como terapias adyuvantes ${ }^{4,5}$ en algunas neoplasias. Finalmente, terapias adoptivas utilizando CTL estimulados in vitro, han sido probadas en algunos protocolos clínicos, con respuestas clínicas variables ${ }^{6}$.

\section{LOS LNFOCITOS T CITOTÓXICOS Y LA RESPUESTA INMUNE ANTITUMORAL}

Experimentos pioneros demostraron que el crecimiento de tumores singénicos en ratones podía ser prevenido previa inmunización con el mismo tumor ${ }^{7,8}$. Guiados por estos estudios, se ha observado que los linfocitos $\mathrm{T}$ humanos también son capaces de lisar específicamente tumores autólogos in vitro ${ }^{9}$. Además, las células $\mathrm{T}$ proliferan en respuesta a la estimulación con células tumorales autólogas, secretando citoquinas como IL-2, IFN- $\gamma$, factor estimulante de colonias de granulocitos y macrófagos (GM-CSF) y factor de necrosis tumoral-alpha (TNF- $\alpha)^{10,11}$. Las células T antitumorales pueden ser expandidas en grandes cantidades in vitro y transferidas adoptivamente, con el fin de tratar grandes cargas tumorales ${ }^{6,9}$. Estas observaciones han posibilitado la identificación de antígenos tumorales reconocidos por células $T$ autólogas humanas, usando técnicas de clonamiento molecular ${ }^{12,13}$. Estos resultados en conjunto, proveen evidencias innegables de la existencia de una respuesta, mediada por linfocitos $\mathrm{T}$, contra tumores autólogos. CTL específicos contra melanoma reconocen fragmentos peptídicos de 8-10 aminoácidos derivados de proteínas citoplasmáticas o nucleares asociadas al complejo mayor de histocompatibilidad (MHC) clase $\mathrm{I}^{14,15}$ y poseen capacidad terapéutica, pudiendo inducir la regresión de tumores y sus micrometástasis ${ }^{6,13}$.

\section{Antígenos ASOCiados A MELANOMA}

Durante los últimos diez años, varios antígenos asociados a melanoma (AAM), reconocidos por CTL, fueron identificados y sus epitopos peptídicos caracterizados mediante métodos genéti$\cos ^{12,13}$ y bioquímicos ${ }^{16,17}$. La primera categoría está constituida por los antígenos tumor-específicos, entre los que destaca la familia de genes MAGE $^{18-20}$. Estos antígenos derivan de productos génicos activamente transcritos en varios tipos de tumores, pero no así en células normales y están relacionados con las etapas primarias del desarrollo embrionario ${ }^{18-20}$. Otro grupo de antígenos está constituido por proteínas codificadas por genes mutados, como el derivado de la mutación de la ciclina 4 dependiente de quinasa ${ }^{21}$. El grupo de 
antígenos detectado más frecuentemente en pacientes con melanoma, está formado por los antígenos de diferenciación, también denominados antígenos asociados al tipo de tejido. A esta categoría pertenecen los antígenos melanosomales MART-1/Melan A, gp100 y tirosinasa ${ }^{22-27}$. Los genes que codifican estos antígenos, no solamente se expresan en los melanomas, sino que también en melanocitos normales y en el epitelio pigmentario de la retina, por lo que pueden ser considerados como auto-antígenos ${ }^{22-27}$. Los CTL específicos contra este tipo de antígenos pueden ser aislados de los ganglios linfáticos, de los linfocitos infiltrantes de tumor (TIL) o de los linfocitos de sangre periférica (PBL) de pacientes con melanoma $25-27$. Esto ha sido interpretado como un quiebre de la tolerancia inmunológica contra antígenos propios, debido tal vez, a la sobreexpresión de estas proteínas en las células tumorales. Otro antígeno de estas características es el receptor de melanocortina 1 (MC1R) expresado en melanomas y melanocitos. MC1R es el ligando natural de la hormona peptídica melanocito-estimulante- $\alpha$, involucrada en la proliferación, diferenciación, pigmentación y potencial metastásico de los melanomas ${ }^{28}$. A partir de la clonación de esta molécula ${ }^{28}$, hemos identificado tres péptidos nonaméricos derivados de MC1R, que pueden generar CTL péptido específico a partir de sangre periférica de donantes normales HLA-A2 $+{ }^{29}$. Por otro lado, hemos demostrado que este receptor se sobreexpresa en melanomas cutáneos y oculares en comparación con nevi pigmentados, tejidos normales y otros tumores ${ }^{30}$, fenómeno que podría ser regulado por citoquinas proinflamatorias como IFN- $\gamma$ y TNF- $\alpha$, aparentemente de una forma post transcripcional (resultados no publicados). El estudio de la expresión y regulación de MC1R y otros antígenos tumorales, es relevante por su potencial utilización en inmunoterapia celular contra el melanoma avanzado.

\section{Células dendríticas: PRincipales células} PRESENTADORAS DE ANTÍGENO PROFESIONALES

La capacidad de activar in vitro o in vivo CTL específicos contra melanoma, requiere de una presentación antigénica en un contexto celular especial dado por las células presentadoras de antígenos (APC) $)^{31}$, entre ellas se incluyen los macrófagos, los linfocitos B y las células dendríticas (DC). Estas últimas, juegan un papel fundamental en la generación de una respuesta antitumoral mediada por linfocitos $\mathrm{T}$, ya que poseen la capacidad de capturar antígenos tumorales y presentarlos asociados a las moléculas MHC $^{31,32}$. Además, expresan gran cantidad de moléculas coestimuladoras, las que proveen señales cruciales que garantizan la efectividad de la respuesta mediada por linfocitos $\mathrm{T}^{32,33}$. Las DC, también llamadas APC profesionales, se encuentran estratégicamente localizadas en los sitios de concentración antigénica, internalizan, procesan y presentan eficientemente antígenos solubles en el contexto de MHC clase I y II, siendo las más eficientes en la inducción de una respuesta primaria de linfocitos $\mathrm{T}^{32-34}$. Las DC fueron ya visualizadas en la piel como células de Langerhans en 1868, pero su caracterización comenzó hace solamente 25 años ${ }^{32-34}$.

Los principales obstáculos para la caracterización y utilización de DC (baja frecuencia relativa y la falta de marcadores celulares específicos), sólo han podido ser superados recientemente. En efecto, cantidades relativamente altas de DC, pueden obtenerse in vitro a partir de monocitos de sangre periférica estimulados con GM-CSF e interleuquina-4 (IL-4) ${ }^{34-36}$.

Fisiológicamente, las DC se originan en médula ósea a partir de progenitores hematopoyéticos CD34+. Muchas citoquinas contribuyen al crecimiento y diferenciación de las DCs, como el ligando de c-Kit y el de Flt-3, que corresponden a proteínas de transmembra que se unen a receptores de tirosina-quinasa ${ }^{37}$. Presumiblemente, las DCs migran a través del torrente sanguíneo, desde la médula ósea hacia los tejidos no linfoides, donde se tornan células residentes en un estado de inmadurez, con alta capacidad fagocítica y endocítica ${ }^{38-40}$. Aunque estas DCs carecen de requisitos para estimular a las células $\mathrm{T}$, tales como expresión de moléculas coestimuladoras y poseen una baja expresión de MHC, están extremadamente bien equipadas para capturar antígenos $32,39-42$, por mecanismos que incluyen la fusión de membranas ${ }^{43}$, la pinocitosis y endocitosis mediada por receptores Fc $\gamma$ tipo I (CD64) y II (CD32) (tomados de complejos inmunes o partículas opsonizadas) ${ }^{41}$, fagocitosis de fragmentos 
celulares apoptóticos y necróticos a través de CD36 y las integrinas $\alpha_{\mathrm{v}} \beta_{3}$ y $\alpha_{\mathrm{v}} \beta_{5}{ }^{42}$, y la endocitosis de estructuras virales y bacterianas ${ }^{40}$. Todos estos fenómenos constituyen un evento clave en la inducción de la maduración de las DCs. Una vez capturado el antígeno, ellas migran a los órganos linfoides secundarios como nódulos linfáticos y bazo, donde completan su maduración y se convierten en células presentadoras de antígenos capaces de seleccionar y activar linfocitos antígeno-específicos ${ }^{32-40}$. Esto permite la diversificación de la respuesta y la activación de efectores antígeno-específico como CTL, células $ß \mathrm{y}$ también efectores no-específicos como células $\mathrm{NK}$, macrófagos y eosinófilos ${ }^{44}$. Existen otros numerosos factores que inducen o regulan la maduración de las DC, incluyendo LPS, ADN bacteriano y el balance entre las señales proinflamatorias y antiinflamatorias en el microambiente local ${ }^{45}$. El proceso de maduración está asociado a una serie de eventos coordinados tales como, el aumento en la expresión de MHC clase I y II y de moléculas coestimuladoras como CD 40, CD58, CD80 y CD86, pérdida de receptores fagocíticos y endocíticos, pérdida de estructuras adhesivas y adquisición de una alta motilidad celular $32,34,40,45$.

\section{CELULAS DENDRÍTICAS Y MELANOMA}

La habilidad única de las DC para inducir una respuesta inmune primaria, hace de ellas las mejores candidatas para ser usadas en protocolos de vacunación en cáncer ${ }^{32-40}$. De hecho, DC cargadas adecuadamente con antígenos asociados a tumor han inducido una respuesta inmune protectora y eficaz en la eliminación de los tumores en modelos animales ${ }^{46-50}$.

Existen varios ensayos clínicos para el tratamiento de neoplasias avanzadas reportados en los últimos 5 años (Tabla 1) ${ }^{51}$. Muchos de los estudios pilotos de vacunación con DC han sido realizados en melanoma, debido a que esta neoplasia posee antígenos inmunológicamente bien definidos. Debido al limitado espacio hemos seleccionado algunos estudios. El primero, realizado por Nestle y $\operatorname{cols}^{52}$, utilizó DC cargadas con péptidos o lisados tumorales y hemocianina de Keyhole Limpet (KLH) como adyuvante, las que fueron administradas intranodalmente a pacientes con melanoma ${ }^{52}$.
En este estudio fueron reportadas respuestas objetivas en 5 de los 16 pacientes evaluados (dos respuestas completas y tres respuestas parciales) ${ }^{52}$. Menciones actuales sobre este estudio51 muestran que la respuesta clínica se ha mantenido por algunos años. Otros estudios que utilizaron el péptido MAGE-3, lograron una buena respuesta péptido específica in vitro, sin embargo ésta no se correlacionó con una respuesta clínica, posiblemente por la baja presentación de este péptido restringido a HLA-A2 en la mayoría de las células de melanoma ${ }^{53}$. Recientemente, fue reportado que DC maduras y criopreservadas cargadas con múltiples péptidos restringidos a MHC clase I y clase II, inducían una respuesta rápida y específica de células tipo Th1, productoras de IFN- $\gamma$ contra el antígeno MAGE-354.

\section{VACUNACIÓN DE PACIENTES CON MELANOMA UTILZZANDO CÉLULAS DENDRÍTICAS PULSADAS CON EXTRACTOS DE MELANOMA ALOGÉNICO}

Recientemente, hemos finalizado en Chile el primer ensayo clínico de fase I para tratamiento de melanoma maligno avanzado, utilizando vacunas de células dendríticas cargadas con lisados tumorales alogénicos.

Nuestro estudio consistió en una adaptación del protocolo de Nestle y col ${ }^{52}$ y fue aprobada por el Comité de Bioética para estudios en seres humanos de la Universidad de Chile. Los 13 pacientes con melanoma avanzado incluidos, fueron informados de los alcances de este estudio y de las perspectivas reales de éxito, antes de someterlos a una leucoféresis. A partir de monocitos incubados durante 7 días en presencia de IL-4 y de GM-CSF se obtuvieron células dendríticas. El día 6, las DC fueron pulsadas con lisados tumorales provenientes de tres líneas de melanoma alogénicas, y luego maduradas con TNF- $\alpha$ por 12 a $18 \mathrm{~h}$. Las DC maduras fueron tipificadas por citometría de flujo. Aproximadamente entre 3,5 y $15 \times 10^{6}$ DC pulsadas fueron inyectadas subcutáneamente (sc). Esta rutina se repitió semanalmente por 4 veces. Luego de la cuarta dosis se evaluó el estado general del paciente, las posibles regresiones clínicas, los efectos colaterales negativos y además los efectos del tratamiento en el sistema inmune. Esto se realizó mediante ensayos in vivo 
Tabla 1. Ensayos clínicos utilizando células dendríticas en melanoma maligno

\begin{tabular}{|c|c|c|c|c|c|}
\hline Referencias & $\mathrm{N}^{\circ}$ de pacientes & Fuente de DC & $\begin{array}{l}\text { Antígeno empleado } \\
\text { para pulsar las DC }\end{array}$ & $\begin{array}{l}\text { Respuesta } \\
\text { inmunológica }\end{array}$ & $\begin{array}{l}\text { Respuesta } \\
\text { clínica }\end{array}$ \\
\hline $\begin{array}{l}\text { Bedrosian I, et al. } \\
\text { J Clin Oncol. } \\
\text { 2003; 21(20): 3826-3835. }\end{array}$ & 27 pacientes & $\begin{array}{l}\text { Monocitos de } \\
\text { sangre periférica }\end{array}$ & gp100, tirosinasa, MART-1 & $\begin{array}{l}\text { Inducción de respuesta } \mathrm{T} \\
\text { especifica en } 20 / 27 \text { pacientes }\end{array}$ & $3 \mathrm{PR}$ \\
\hline $\begin{array}{l}\text { O'Rourke MG, et al. } \\
\text { Cancer Immunol Immunother. } \\
\text { 2003; 52(6): 387-395. }\end{array}$ & 17 pacientes & $\begin{array}{l}\text { Monocitos de } \\
\text { sangre periférica }\end{array}$ & Lisados tumorales autólogos & $\begin{array}{l}\text { DTH positiva en } \\
4 / 17 \text { pacientes }\end{array}$ & $\begin{array}{l}3 \mathrm{CR} \\
3 \mathrm{PR} \\
6 \mathrm{PD}\end{array}$ \\
\hline $\begin{array}{l}\text { Schuler-Thumer B et al. } \\
\text { J Exp Med. } \\
\text { 2002; 195(10): 1279-1288. }\end{array}$ & 16 pacientes & $\begin{array}{l}\text { Monocitos de } \\
\text { sangre periférica }\end{array}$ & $\begin{array}{l}\text { MART-1, tyrosinase, } \\
\text { MAGE-3, y gp100 }\end{array}$ & $\begin{array}{l}\text { Inducción de respuesta } \\
\text { Th1 específica en todos } \\
\text { los pacientes }\end{array}$ & $\begin{array}{l}1 \mathrm{CR} \\
8 \mathrm{SD} \\
7 \mathrm{PD}\end{array}$ \\
\hline $\begin{array}{l}\text { Banchereau J et al. } \\
\text { Cancer Res. } \\
\text { 2001; 61(17): 6451-6458. }\end{array}$ & 18 pacientes & $\begin{array}{l}\text { Progenitores } \\
\text { CD34t }\end{array}$ & $\begin{array}{l}\text { MART-1, tyrosinase, } \\
\text { MAGE-3, y gp100 }\end{array}$ & $\begin{array}{l}\text { Inducción de respuesta } \\
\text { T específica en } 18 / 16 \text { pacientes }\end{array}$ & $7 \mathrm{PR}$ \\
\hline $\begin{array}{l}\text { Lau R et al. } \\
\text { J Immunother. } \\
2001 \text {; 24(1): 66-78. }\end{array}$ & 16 pacientes & $\begin{array}{l}\text { Monocitos de } \\
\text { sangre periférica }\end{array}$ & Tirosinasa y gp100 & $\begin{array}{l}\text { Inducción de respuesta } \mathrm{T} \\
\text { específica en } 16 / 5 \text { pacientes }\end{array}$ & $\begin{array}{l}1 \mathrm{CR} \\
2 \mathrm{PR} \\
1 \mathrm{SD}\end{array}$ \\
\hline $\begin{array}{l}\text { Panelli MC et al, } \\
\text { J Immunother. } \\
\text { 2000; 23(4): 487-498. }\end{array}$ & 10 pacientes & $\begin{array}{l}\text { Monocitos de } \\
\text { sangre periférica }\end{array}$ & gp100 y MART-1 & $\begin{array}{l}\text { Inducción de respuesta } \mathrm{T} \\
\text { específicas en } 1 / 5 \text { pacientes }\end{array}$ & 1PR \\
\hline $\begin{array}{l}\text { Mackensen A et al. } \\
\text { Int J Cancer. } \\
\text { 2000; 86(3): 385-392. }\end{array}$ & 14 pacientes & $\begin{array}{l}\text { Progenitores } \\
\text { hematopoyéticos } \\
\text { CD34+ }\end{array}$ & $\begin{array}{l}\text { MART-1, tirosinasa, } \\
\text { MAGE-3 y gp100 }\end{array}$ & $\begin{array}{l}\text { Inducción de respuesta } \mathrm{T} \\
\text { específica en todos los pacientes }\end{array}$ & $\begin{array}{c}2 \\
\text { respuestas } \\
\text { clínicas }\end{array}$ \\
\hline $\begin{array}{l}\text { Thurner B et al. } \\
\text { J Exp Med. } \\
\text { 1999; 190(11): 1669-1678. }\end{array}$ & 11 pacientes & $\begin{array}{l}\text { Monocitos de } \\
\text { sangre periférica }\end{array}$ & MAGE-3 & $\begin{array}{l}\text { Expansión de LTCD8+ } \\
\text { antígeno específicos en } \\
\text { 8/11 pacientes }\end{array}$ & $\begin{array}{l}4 \mathrm{CR} \\
2 \mathrm{PR} \\
5 \mathrm{PD}\end{array}$ \\
\hline $\begin{array}{l}\text { Nestle FO et al. } \\
\text { Nat Med. } \\
\text { 1998; 4(3): 328-332. }\end{array}$ & 16 pacientes & $\begin{array}{l}\text { Monocitos de } \\
\text { sangre periférica }\end{array}$ & $\begin{array}{l}\text { Lisados tumorales } \\
0 \text { péptidos }\end{array}$ & $\begin{array}{l}\text { DTH positiva en } \\
\text { 11/16 pacientes }\end{array}$ & $\begin{array}{l}2 \mathrm{CR} \\
3 \mathrm{PR}\end{array}$ \\
\hline Escobar et al. 2004 & 13 pacientes & $\begin{array}{l}\text { Monocitos de } \\
\text { sangre periférica }\end{array}$ & Lisados tumorales & $\begin{array}{l}\text { Inducción de respuesta T } \\
\text { especifica en } 7 / 12 \text { y DTH } \\
\text { positiva en } 6 / 12 \text { pacientes }\end{array}$ & $2 \mathrm{PR}$ \\
\hline
\end{tabular}

CR: Respuesta completa SD: Enfermedad estable

PR: Respuesta parcial PD: Progresión de la enfermedad 
de hipersensibilidad de tipo retardada (DTH), utilizando extractos de melanoma y sus respectivos controles. Los ensayos in vitro planificados incluyeron, la detección de precursores de linfocitos T específicos contra células tumorales mediante ELISPOT ${ }^{53}$, producción de citoquinas, ensayos de proliferación, y ensayos de cuantificación de la relación CD4/CD8 mediante citometría de flujo.

En general los resultados obtenidos, que serán enviados a publicación una vez completado su análisis, se pueden resumir de la siguiente manera:

- No se observaron efectos adversos a la aplicación de células dendríticas subcutáneamente, a excepción de un paciente que mostró fiebre leve y artralgia, probablemente no asociada a la vacuna.

- Se observó efectos inmunológicos in vitro, medidos por ELISPOT, en $60 \%$ de los pacientes tratados, con un aumento de precursores de linfocitos $\mathrm{T}$ específicos contra células tumorales en la sangre de los pacientes.

- Se observó reacción DTH en 50\% de los pacientes tratados al inyectarse extracto tumoral subcutáneamente luego de las vacunaciones.

- Se observó regresión parcial o respuesta mixta en 2 pacientes. Una regresión de metástasis subcutáneas pectorales y una regresión de metástasis cutánea.

- En la mayoría de los casos se observó estabilidad en la enfermedad, aunque no se puede concluir que exista una relación significativa entre vacunación y sobrevida de los pacientes tratados.

\section{INTERLEUQUINA-2}

La interleuquina 2 (IL-2) es una glicoproteína de $15 \mathrm{kDa}$ sintetizada y secretada principalmente por linfocitos $\mathrm{T}$ ayudadores (Th) como efecto de la activación mediada por mitógenos o por la interacción entre el complejo TCR/CD3 con el complejo MHC, en la superficie de células presentadoras de antígenos ${ }^{55,56}$. La respuesta de los linfocitos $\mathrm{T}$ a la activación es la inducción de la producción de IL-2 y la expresión en la membrana de su receptor, teniendo como consecuencia la expansión clonal de los linfocitos $\mathrm{T}$ específicos para el antígeno. La IL-2 puede actuar como un factor autocrino o paracrino, estimulando la activación de otras células del sistema inmunológico como linfocitos $\mathrm{T}$ CD8+, células $\mathrm{B}^{57-59}$, células natural killer $(\mathrm{NK})^{60}$ y los llamados linfocitos activados por citoquinas (LAK) ${ }^{61,62}$. Otros subtipos celulares influenciados por la IL-2 son los neutrófilos ${ }^{63}$, los linfocitos T gamma-delta ${ }^{64}$ y los monocitos ${ }^{65}$, que han mostrado efectos tales como activación o aumento de su sobrevivencia cuando han sido expuestos a la citoquina.

El gen de IL-2 fue posteriormente clonado y expresado en células eucariontes ${ }^{66}$ y E coli ${ }^{67}$. El análogo recombinante humano de la IL-2 (rhIL-2) es conocido como PROLEUKIN ${ }^{\circledR}$ (aldesleukin). La IL-2 recombinante ha demostrado efectos promisorios como droga anticancerígena, debido a la capacidad de inducir la activación y proliferación de las poblaciones celulares LAK y de TIL68,69. Desde 1985, los efectos mediados por IL-2 observados en carcinoma renal y melanoma, le han valido la reciente aprobación por la Administración de Fármacos y Alimentos de los Estados Unidos (FDA) para el tratamiento de estas neoplasias $^{68-72}$.

Aunque la utilización de rhIL-2 ha resultado ser una de las estrategias más efectivas en el tratamiento del carcinoma renal y melanoma avanzado, la terapia basada en la aplicación de dosis altas de IL-2 intravenosamente, no resulta apropiada para todos los pacientes. Su utilización está restringida a pacientes mayores de edad con un buen estado general ${ }^{73}$. En la mayoría de los pacientes, los efectos colaterales aparecen solamente durante el tratamiento, siendo controlados en tres días luego de finalizado éste. Por esto, es recomendable que la aplicación de IL-2 se realice en un centro que cuente con la supervisión médica adecuada. Los efectos adversos de la rIL-2 se basan en la utilización de dosis altas $\left(18 \times 10^{6}\right.$ $\mathrm{IU} / \mathrm{m}^{2}$ ) y en su administración intravenosa (Tabla 2). La experiencia basada en estudios clínicos realizados en el Instituto Karolinska de Suecia, por miembros de nuestro equipo ${ }^{74}$ y la experiencia internacional $^{75-77}$ indican que las dosis bajas $\left(2,4 \times 10^{6} \mathrm{IU} / \mathrm{m}^{2}\right)$ y la aplicación subcutánea, mantiene los mismos efectos beneficiosos para los pacientes eliminando casi absolutamente los efectos adversos ${ }^{74,77}$. 


\section{OPTIMIZACIÓN DE LA VACUNACIÓN CON DC EN MELANOMA}

Existen varios obstáculos que deben ser vencidos para permitir que este tipo de tratamiento pueda ser efectivo en pacientes. Primero, la inmunización se ve dificultada debido al estado de inmunosupresión en que muchos pacientes se encuentran producto de la carga tumoral, de la quimioterapia ${ }^{78}$ u otros factores aún no determinados. Otra dificultad, es la capacidad de los tumores de escapar al reconocimiento del sistema inmune ${ }^{79}$. Estas estrategias de escape, van desde la inhibición de la presentación antigénica, hasta la producción de sustancias inmunosupresoras como las citoquinas TFG- $\beta$ e IL-10 ${ }^{79}$. La importancia relativa de estos posibles mecanismos en la reducción del potencial de la inmunoterapia, aún no ha sido establecida.

Tabla 2. Efectos colaterales reportados en ensayos clínicos con PRO LE UKIN IL-2, que involucran a un total de 525 pacientes ya sea con carcinoma renal o melanoma metastásico

\begin{tabular}{|c|c|c|c|}
\hline Sistema & Grado3 & Grado 4 & Todos los eventos \\
\hline Generales & $70 \quad(13 \%)$ & $0 \quad(0 \%)$ & $271 \quad(52 \%)$ \\
\hline Escalofríos & $29 \quad(6 \%)$ & $5 \quad(1 \%)$ & 154 (29\%) \\
\hline Fiebre & $43 \quad(8 \%)$ & $0 \quad(0 \%)$ & $143(27 \%)$ \\
\hline Malestar infección & $29(6.0 \%)$ & $7 \quad(1 \%)$ & $66(13 \%)$ \\
\hline \multicolumn{4}{|l|}{ Sistema cardiovascular } \\
\hline Hipotensión & (39) & $15 \quad(3 \%)$ & 375 (71\%) \\
\hline Desórdenes cardiovasculares & $(7)$ & $7 \quad(1 \%)$ & 59 (11\%) \\
\hline \multicolumn{4}{|l|}{ Sistema Digestivo } \\
\hline Diarrea & 113 (22\%) & $10 \quad(2 \%)$ & 350 (67\%) \\
\hline Vómitos & $111(21 \%)$ & $7 \quad(1 \%)$ & $261 \quad(50 \%)$ \\
\hline Náuseas & $25 \quad(5 \%)$ & $0 \quad(0 \%)$ & $186(35 \%)$ \\
\hline Náuseas y vómitos & $25 \quad(5 \%)$ & $2 \quad(0 \%)$ & $101(19 \%)$ \\
\hline \multicolumn{4}{|l|}{ Hematológicos } \\
\hline Trombocitopenia & 59 (11\%) & $5 \quad(1 \%)$ & 192 (37\%) \\
\hline Anemia & $15 \quad(3 \%)$ & $1 \quad(0 \%)$ & $150(29 \%)$ \\
\hline \multicolumn{4}{|l|}{ Metabólicos y Nutricionales } \\
\hline Bilimubinemia & $30 \quad(6 \%)$ & $13(2 \%)$ & $210(40 \%)$ \\
\hline Aumento de la creatinina & $14 \quad(3 \%)$ & $5 \quad(1 \%)$ & 174 (33\%) \\
\hline Aumento de SGOT & $17 \quad(3 \%)$ & $3(1 \%)$ & 122 (23\%) \\
\hline \multicolumn{4}{|l|}{ Sistema Nervioso Central } \\
\hline Confusión & $57 \quad(11 \%)$ & $5 \quad(1 \%)$ & 177 (34\%) \\
\hline Somnolencia & $19 \quad(4 \%)$ & $2 \quad(0 \%)$ & 115 (22\%) \\
\hline \multicolumn{4}{|l|}{ Sistema Respiratorio } \\
\hline Diseña & $52 \quad(10 \%)$ & $5 \quad(1 \%)$ & 224 (43\%) \\
\hline Desórdenes respiratorios & $15 \quad(3 \%)$ & $14 \quad(3 \%)$ & 59 (11\%) \\
\hline \multicolumn{4}{|l|}{ Sistema urogenital } \\
\hline Oliguria & $137 \quad(26 \%)$ & $33(6 \%)$ & 333 (63\%) \\
\hline Anuria & $13(1 \%)$ & $25 \quad(5 \%)$ & $36 \quad(7 \%)$ \\
\hline
\end{tabular}

Efectos adversos del grado 3 y 4 en $>0$ igual a $3 \%$ de los pacientes tratados $(n=525)$. Efectos adversos grado 4 son aquellos que comprometen la vida de los pacientes.

La tasa de muerte relacionada al uso de la droga en 255 pacientes con carcinoma renal metastásico, que recibieron PROLEUKIN IL-2 fue de 4\% (11/255). La tasa de muerte relacionada al uso de la droga en 270 pacientes con melanoma metastásico, que recibieron PROLEUKIN IL-2 fue de 2\% (6/270). 
De todas maneras, resulta importante indagar en estos obstáculos y desarrollar protocolos clínicos adecuados que desplieguen todo el potencial de la inmunoterapia basada en vacunas, la cual ha sido tan convicentemente demostrada en modelos murinos. Basados en los datos anteriores, hemos decidido aplicar un protocolo optimizado que combine alternadamente las vacunas de células dendríticas, con la utilización de dosis bajas de rhIL-2 para el fortalecimiento del sistema inmunológico. Esta optimización está basada en estudios realizados por Rosenberg y cols del Instituto Nacional de Salud de los Estados Unidos de América (NIH), que obtiene

\section{REFERENCIAS}

1. PawLik TM, Sondak VK. Malignant melanoma: current state of primary and adjuvant treatment. Crit Rev Oncol Hematol 2003; 45: 245-64.

2. Medina E, KaempFFer A. Mortalidad del adulto en Chile. Rev Med Chile 2000; 128: 1144-9.

3. Silverman LB, Weinstein HJ. Treatment of childhood leukemia. [Review]. Curr Opin Oncol 1997; 9: 26-33.

4. Vey N, Viens P, Fossat C, Olive D, Sainty D, BAUME D ET AL. Clinical and biological effects of gamma interferon and the combination of gamma interferon and interleukin-2 after autologous bone marrow transplantation. Eur Cytokine Netw 1997; 8: 389-94.

5. Richards JM, Gale D, Mehta N, Lestingi T. Combination of chemotherapy with interleukin-2 and interferon alpha for the treatment of metastatic melanoma. J Clin Oncol 1999; 17: 651-7.

6. Rosenberg SA, Spiess P, LAFreniere R. A new approach to the adoptive immunotherapy of cancer with tumor-infiltrating lymphocytes. Science. 1986; 233: 1318-21.

7. Prehn RT, Main JM. Immunity to methylcholanthrene-induced sarcomas. J Natl Cancer Inst 1957; 18: 769-78.

8. Lein G, Sjogren Ho, Klein E, Hellstrom Ke. Demonstration of resistance against methylcholanthrene-induced sarcomas in the primary autochthonous host. Cancer Res 1960; 20: 1561-72. mejores respuestas al combinar vacunas de células dendríticas cargadas con péptidos antigénicos modificados en presencia de IL-2, que en ausencia de ésta ${ }^{80}$. Por otra parte, para evitar los efectos colaterales de las dosis altas de IL-2, que si bien son manejables, afectan momentáneamente la calidad de vida de los pacientes, utilizaremos dosis bajas que no producen efectos adversos importantes ${ }^{74}$ 78. Muy pocos estudios en el ámbito mundial se han desarrollado en el área, los que en general demuestran que la IL-2 potenciaría la capacidad de las vacunas de células dendríticas de inducir respuesta inmunológica.

9. Topalian SL, Solomon D, Rosenberg SA. Tumorspecific cytolysis by lymphocytes infiltrating human melanomas. J Immunol 1989; 142: 3714-25.

10. Ітон K, Platsoucas DC, Balch CM. Autologous tumor-specific cytotoxic $\mathrm{T}$ lymphocytes in the infiltrate of human metastatic melanomas. Activation by interleukin 2 and autologous tumor cells, and involvement of the $\mathrm{T}$ cell receptor. J Exp Med 1988; 168: 1419-41.

11. Barth RJ Jr, Mule JJ, Spiess PJ, Rosenberg SA. Interferon gamma and tumor necrosis factor have a role in tumor regressions mediated by murine CD8+ tumor-infiltrating lymphocytes. J Exp Med 1991; 173: 647-58.

12. Boon T, Cerottini JC, Van Den Eynde B, Van Der Bruggen P, Van Pel A. Tumor antigens recognized by $\mathrm{T}$ lymphocytes. Annu Rev Immunol 1994; 12: 337-65.

13. Boon T, Gajewski TF, Coulie PG. From defined human tumor antigens to effective immunization Immunol. Today 1995; 16: 334-6.

14. Zinkernagel RM, Doherty PC. Restriction of in vitro $\mathrm{T}$ cell-mediated cytotoxicity in lymphocytic choriomeningitis within a syngeneic or semiallogeneic system. Nature 1974; 248: 701-2.

15. Townsend AR, Gotch FM, Davey J. Cytotoxic T cells recognize fragments of the influenza nucleoprotein. Cell 1985; 42: 457-67.

16. Falk K, Rotzschke O, Deres K, Metzger J, Jung G, RAMMENSEE HG. Identification of naturally processed viral nonapeptides allows their quantifi- 
cation in infected cells and suggests an allelespecific $\mathrm{T}$ cell epitope forecast. J. Exp Med 1991; 174: 425-34.

17. Sungluff CL JR, Cox AL, Henderson RA, Hunt DF, EngelHard VH. Recognition of human melanoma cells by HLA-A2.1-restricted CTL is mediated by at least six shared peptide epitopes. J Immunol 1993; 150: 2955-63.

18. Traversari C, Van der Bruggen P, Luescher IF, Lurquin C, Chomez P, Van Pel A et al. A nonapeptide encoded by human gene MAGE-1 is recognized on HLA-A1 by cytolytic T lymphocytes directed against tumor antigen MZ2E. J Exp Med 1992; 176: 1453-7.

19 Gaugler B, Van Den Eynde P, Van Der Bruggen P, Romero J, Gaforio E, De Plaen B et al. Human gene MAGE-3 codes for an antigen recognized on a melanoma by autologous cytolytic $\mathrm{T}$ lymphocytes. J Exp Med 1994; 179: 921-30.

20. Tanzarelia S, Russo V, Lionello I, Dalerba P, RigatTi D, Bordignon C et al. Identification of a promiscuous T-cell epitope encoded by multiple members of the MAGE family. Cancer Res 1999; 59: 2668-74.

21. Wölfel T, Hauer $M$, Schneider J, Serrano $M$, Wölfel C, Klehmann-Hieb E et al. A p16INK4ainsensitive CDK4 mutant targeted by cytolytic $\mathrm{T}$ lymphocytes in a human melanoma. Science 1995; 269: 1281-4.

22. Coulle PG, Brichard V, Van Peal T, Wölfel J, Schneider C, Traversari S et al. A new gene coding for a differentiation antigen recognized by autologous cytolytic T lymphocytes on HLAA2 melanomas. J Exp Med 1994; 180: 35-42.

23. Kamakami $Y$, Eliyahu CH, Delgado PF, Robbins $\mathrm{K}$, Sakaguchi E, Appelia J et al. Identification of a human melanoma antigen recognized by tumor-infiltrating lymphocytes associated with in vivo tumor rejection. Proc Natl Acad Sci USA 1994; 91: 6458-62.

24. Kanakami Y, Eliyahu CH, Delgado PF, Robbins L, Rivoltini SL, Topalan T et al. Cloning of the gene coding for a shared human melanoma antigen recognized by autologous T cells infiltrating into tumor. Proc Natl Acad Sci USA 1994; 91: 3515-9.

25. Kawakami YS, Eliyahu K, Sakaguchi PF, Robbins L, Rivoltini $\mathrm{J}$, YanneLi E. Identification of the immunodominant peptides of the Mart-1 human melanoma antigen recognized by the majority of HLA-A2 restricted tumor infiltrating lymphocytes. J Exp Med 1994; 180: 347-52.

26. Kawakami YS, Eliyahu C, Jennings K, Sakaguchi $X$, Kang S, Southwood P ET aL. Recognition of multiple epitopes in the human melanoma antigen gp100 by tumor infiltrating T lymphocytes associated with in vivo tumor regression. J Immunol 1995; 154: 3961-8.

27. Brichard V, Van Pel A, Wölfel T, Wolfel C, De Plaen E, Lethe B et al. The tyrosinase gene coded for an antigen recognized by autologous cytolytic T lymphocytes on HLA-A2 + melanoma. J Exp Med 1993; 178: 489-95.

28. ChHAJLANi V, WikBerg JES. Molecular cloning and expression of the human melanocyte stimulating hormone receptor cDNA. FEBS Letters, 1992; 309: 417-20.

29. Salazar-O nfray F, Nakazawa T, Chhajlani V, PeterSSON M, KarRe K, MasucCi G et al. Synthetic peptides derived from the melanocyte-stimulating hormone receptor MC1R can stimulate HLA-A2-restricted cytotoxic T lymphocytes that recognize naturally processed peptides on human melanoma cells. Cancer Res 1997; 57: 4348-55.

30. Salazar-Onfray F, López M, Lundqvist A, AguirRe A, Escobar A, Serrano A et al. Tissue distribution and differential expression of melanocortin 1 receptor, a malignant melanoma marker. Br J Cancer 2002; 87: 414-22.

31. Delves PJ, Roitt IM. The immune system. First of two parts. N Engl J Med. 2000; 343: 37-49.

32. Banchereau J, Steinman RM. Dendritic cells and the control of immunity. (Review) Nature 1998; 392: 245-52.

33. LuU Y, Janeway CA JR. Cells that present both specific ligand and co-stimulatory activity are the most efficient inducers of clonal expansion of normal CD4 T cell. Proc Natl Acad Sci 1992; 89: 3845-9.

34. Steinman RM, Conn ZA. Identification of a novel cell type in peripheral lymphoid organs of mice functional properties in vitro. J Exp Med 1973; 137: 1142-62.

35. Sallusto F, Lanzavecchia A. Efficient presentation of soluble antigen by cultured human dendritic 
cells is mainteined by granulocyte/macrophage colony-stimulating factor plus interleukin 4 and downregulated by tumor necrosis factor $\alpha$. J Exp Med 1994; 179: 1109-18.

36. Reddy A, Sapp M, Feldman M, Subklewe $M$, BHARDWAJ N. A monocyte conditioned medium is more effective than defined cytokines in mediating the terminal maturation of human dendritic cells. Blood 1997; 90: 3640-6.

37. Young JW, Szabolcs P, Moore MAS. Identification of dendritic cell colony-forming units among normal CD4+ bone marrow progenitors that are expanded by c-kit-ligand and yield pure dendritic cell colonies in the presence of granulocyte/macrophage colony-stimulating factor and tumor necrosis factor $\alpha$. J Exp Med 1995; 182: 1111-20.

38. Sallusto F, Cella M, Danieli C, Lanzaveccihia A. Dendritic cells use macropinocytosis and the mannose receptor to concentrate macromolecules in the major histocompatibility complex class II compartment: Downregulation by cytokines and bacterial products. J Exp Med 1995; 182: 389-400.

39. Reis E Sousa C, Stahl PD, Austyn JM. Phagocytosis of antigens by langerhands cells in vitro. J Exp Med 1993; 178: 509-19.

40. Banchereau J, Briene F, Caux C, Davoust J, LeBeCQue S, LuU YJ. Immunology of dendritic cells. Ann Rev Immunol 2000; 18: 767-811.

41. Fanger NA, Wardwell KL, Shen L, Tedder TF, GuYre PM. Type I (CD64) and type II (CD32) Fcggg receptor-mediated phagocytosis by human blood dendritic cells. J Immunol 1996; 157: 541-8.

42. Albert ML, Pearce SF, Francisco LM, Sauter B, Roy P, Silverstein RL. A immature dendritic cells phagocytose apoptotic cells via $\alpha v ß 5$ and CD36, cross-present antigens to cytotoxic $\mathrm{T}$ lymphocytes. J Exp Med 1998; 188: 1359-68.

43. Russo V, Zhou D, Sartirana C, Rovere P, Vilia A, Rossini $S$ ET AL. Acquisition of intact allogeneic human leukocyte antigen molecules by human dendritic cells. Blood. 2000; 95: 3473-7.

44. Lambrecht BN, Salomon B, Klatzmann D, Pauwels RA. Dendritic cells chronic eosinophilic airway inflammation are required for the development of in response to inhaled antigen in sensitized mice. J Immunol 1998; 160: 4090-7.
45. Rescigno M, Granucci F, Citterio S, Foti M, Ricciardi-Castagnol P. Coordinated events during bacteria-induced DC maduration. Immunol Today 1999; 20: 200-3.

46. Paglia P, Chiodoni C, Rodolfo M, Colombo MP. Murine dendritic cells loaded in vitro with soluble protein prime cytotoxic $\mathrm{T}$ lymphocytes against tumor antigen in vivo. J Exp Med 1996; 183: 317-22.

47. Porgador A, Gilboa E. Bone marrow-generated dendritic cells pulsed with a class I-restricted peptide are potent inducers of cytotoxic $\mathrm{T}$ lymphocytes. J Exp Med 1995; 182: 255-60.

48. Song W, Kong H, Carpenter H, Tori H, GransTEIN R, RafII S. Crystal Dendritic Cells genetically modified with an adenovirus vector encoding the cDNA for a model antigen induce protective and therapeutic antitumor immunity J Exp Med 1997; 186: 1247-56.

49. Boczkowski D, Nair SK, SNyder D, Gilboa E Dendritic cells pulsed with RNA are potent antigen-presenting cells in vitro and in vivo. J Exp Med 1996; 184: 465-72.

50. Toes R, Van Der Voort Ein, Schoenberger SP, Drjfrhout JW, Van Bloois L, Storm G. Enhancement of tumor outgrowth through CTL tolerization after peptide vaccination is avoided by peptide presentation on dendritic cells J Immunol 1998; 160: 4449-56.

51. Shuler G, Shuler-Thurner B, Steinman RM. The use of dendritic cells in cancer immunotherapy. Curr Opin Immunol 2003; 15: 138-47.

52. Nestle Fo, Alujagic S, Giliet M, Sun Y, Grabbe S, DUMmer $R$ Vaccination of melanoma patients with peptide- or tumor lysate-pulsed dentritic cells. Nature Med 1998; 4: 328.

53. Thurner B, Dieckmann D, Keikavoussi P, Bender A, MaczeK C, Jonuleit H. Mage-3 and influenzamatrix peptide-specific cytotoxic $\mathrm{T}$ cells are inducible in terminal stage HLA-A2.1+ melanoma patients by mature monocyte-derived dendritic cells. J Immunol 2000; 165: 3492-6.

54. Thurner B, Schultz ES, Berger TG, Weinlich G, EBNER S, WoerL P. Rapid induction of tumorspecific type $1 \mathrm{~T}$ helper cells in metastatic melanoma patients by vaccination with mature, cryopreserved, peptide-loaded monocytederived dendritic cells. J Exp Med 2002; 195: 1279-88. 
55. Sмiтн KA. T-cell growth factor. Immunol Rev 1980; 51: 257-78.

56. AткіNs MB. Interleukin-2: clinical applications. Semin Oncol 2002; 29(3 Suppl 7): 12-7.

57. Sмгтн KA. Interleukin-2: inception, impact, and implications. Science 1988; 240: 1169-76.

58. Waldmann TA, Goldman CK, Robb RJ, Depper JM, LEONARD WJ, SHarrow SO. Expression of interleukin 2 receptors on activated human B cells. J Exp Med 1984; 160: 1450-66.

59. Zubler RH, Lowenthal JW, Erard F, Hashimoto N, Devos R, Macdonald HR. Activated B cells express receptors for, and proliferate in response to, pure interleukin 2. J Exp Med 1984; 160: 1170-83.

60. Henney CS, Kuribayashi K, Kern DE, Gilus S. Interleukin-2 augments natural killer cell activity. Nature 1981; 291: 335-8.

61. Siegel JP, Sharon M, Smith PL, Leonard WJ. The IL-2 receptor beta chain ( $p 70)$ : role in mediating signals for LAK, NK, and proliferative activities. Science 1987; 238: 75-8.

62. Grimm EA, Mazumder A, Zhang HZ, Rosenberg SA. Lymphokine-activated killer cell phenomenon. Lysis of natural killer-resistant fresh solid tumor cells by interleukin 2-activated autologous human peripheral blood lymphocytes. J Exp Med 1982; 155: 1823-41.

63. Djeu JY, Liu JH, Wei S, Rui H, Pearson Ca, LEONARD WJ. Function associated with IL-2 receptor-beta on human neutrophils. Mechanism of activation of antifungal activity against Candida albicans by IL-2. J Immunol 1993; 150: 960-70.

64. KJeldsen-Kragh J, Quayle AJ, Skalhegg BS, Sioud M, FORRE O. Selective activation of resting human gamma delta $\mathrm{T}$ lymphocytes by interleukin-2. Eur J Immunol 1993; 23: 2092-9.

65. Espinoza-Delgado I, Bosco MC, Musso T, Gusela GL, LONGo DL, VARESIO L ET AL. Interleukin-2 and human monocyte activation. J Leukoc Biol 1995; 57: 13-9.

66. Taniguchi T, Matsui $H$, Fujita $T$, Takaoka $C$, Kashima N, Yoshimoto R, et al Structure and expression of a cloned cDNA for human interleukin-2. Nature 1983; 302: 305-10.

67. Rosenberg SA, Grimm EA, McGrogan M, Doyle M, KaWAsaki E, Koths K et al Biological activity of recombinant human interleukin-2 produced in Escherichia coli. Science 1984; 22: 1412-4.

68. Rosenberg SA, Lotze MT, Muul LM, Chang AE, Avis FP, Leitman S ET AL. A progress report on the treatment of 157 patients with advanced cancer using lymphokine-activated killer cells and interleukin-2 or high-dose interleukin-2 alone. N Eng J Med 1987; 316: 889.

69. RosenBERg SA. The development of new immunotherapies for the treatment of cancer using interleukin-2. Ann Surg 1988; 208: 121-35.

70. Fisher RI, Coltman CA Jr, Doroshow JH, Rayner AA, Hawkins MJ, Mier JW et al. Metastatic renal cancer treated with interleukin-2 and lymphokine-activated killer cells: a phase II clinical trial. Annals of Internal Medicine 1988; 108: 518-23.

71. Weiss GR, Margolin KA, Aronson FR, Sznol M, AtKins MB, Dutcher JP ET AL. A randomized phase II trial of continuous infusion interleukin-2 or bolus injection interleukin-2 plus lymphokine-activated killer cells for advanced renal cell carcinoma. Journal of Clinical Oncology 1992; 10: 275-81.

72. Rosenberg SA, Yang JC, Topalian SL, Schwartzentruber DJ, Weber JS, Parkinson DR et al. Treatment of 283 consecutive patients with metastatic melanoma or renal cell cancer using high-dose bolus interleukin 2. JAMA 1994; 271: 907-13.

73. Sмітн KA. Lowest dose interleukin-2 immunotherapy. Blood 1993; 81: 1414-23.

74. Masucci G, Svensson A, Hansson M, Hansson J, Nakazawa T, Salazar F et al. Efficient harvest of in vivo IL-2-activated CD3+ lymphocytes for adoptive immunotherapy by selective leukapheresis (lymphocytapheresis). J Hematother 1997; 6: 253-60.

75. Fenton RG, Steis RG, Madara K, Zea AH, Ochoa AC, JANIK JE ET AL. A phase I randomized study of subcutaneous adjuvant IL-2 in combination with an autologous tumor vaccine in patients with advanced renal cell carcinoma. J Immunother Emphasis Tumor Immunol 1996; 19: 36474.

76. Rosenberg SA, Zhai Y, Yang JC, Schwartzentruber DJ, Hwu P, Marincola FM et al. Immunizing patients with metastatic melanoma using re- 
combinant adenoviruses encoding MART-1 or gp100 melanoma antigens. J Natl Cancer Inst 1998; 90: 1894-900.

77. O OSTerwijk-Wakka JC, Tiemessen DM, Bleumer I, De Vries IJ, Jongmans W, Adema GJ et al. Vaccination of patients with metastatic renal cell carcinoma with autologous dendritic cells pulsed with autologous tumor antigens in combination with interleukin-2: a phase 1 study. J Immunother 2002; 25: 500-8.

78. MaCkall CL, Fleisher TA, Brown MR, Magrath IT, Shad AT, Horowitz ME ET AL. Lymphocyte deple- tion during treatment with intensive chemotherapy for cancer. Blood 1994; 84: 2221-8.

79. SAlAZAR-OnFRAY F. Interleukin-10: a strategy used by tumors to escape from immunesurveillance. (Review). Med Oncol 1999; 16: 86-94.

80. Dudiey ME, Wunderlich JR, Robiins PF, Yang JC, Hwu P, Schwartzentruber DJ ET al. Cancer regression and autoimmunity in patients after clonal repopulation with antitumor lymphocytes. Science 2002; 298: 850-4. 